\title{
Encapsulated Data Data Type
}

National Cancer Institute

\section{Source}

National Cancer Institute. Encapsulated Data Data Type. NCI Thesaurus. Code C95649.

A data type comprised of data that may be human or machine consumable. 